\title{
Universiteit
}

Leiden

The Netherlands

\section{Parental attachment and childrens socio- emotional development: Some findings on the validity of the adult attachment interview in the Netherlands}

IJzendoorn, M.H. van; Kranenburg, M.J.; Zwart-Woudstra, H.A.; Busschbach, A.M. van; Lambermon, M.W.E.

\section{Citation}

IJzendoorn, M. H. van, Kranenburg, M. J., Zwart-Woudstra, H. A., Busschbach, A. M. van, \& Lambermon, M. W. E. (1991). Parental attachment and childrens socio-emotional development: Some findings on the validity of the adult attachment interview in the Netherlands. Environments, 14(4), 375-394. Retrieved from https://hdl.handle.net/1887/1080

Version: $\quad$ Not Applicable (or Unknown)

License: $\quad$ Leiden University Non-exclusive license

Downloaded from: $\quad$ https://hdl.handle.net/1887/1080

Note: To cite this publication please use the final published version (if applicable). 


\title{
Parental Attachment and Children's Socio-emotional Development: Some Findings on the Validity of the Adult Attachment Interview in The Netherlands
}

\author{
Marinus H. van IJzendoorn, Marian J. Kranenburg, Hylda \\ A. Zwart-Woudstra, Agnes M. van Busschbach, and Mirjam \\ W.E. Lambermon \\ Center for Child and Family Studies, Leiden University, The Netherlands
}

\begin{abstract}
In this study, the Adult Attachment Interview (AAI) was applied in The Netherlands, to test certain aspects of its validity, and to provide information about its relation to toddlers' socio-emotional adaptation. In the second year of life, a sample of 80 infants were seen with their father, mother, and professional caregiver in the Strange Situation procedure, and in a free-play situation to assess caregivers' sensitivity. Two years later, 68 children participated in a follow-up study, involving mothers, fathers, and professional caregivers. Parents were interviewed with the AAI, and completed the Parental Bonding Instrument that measures attachment experiences in childhood. Parents also completed the Nijmegen-California Q-sort, to measure their children's ego-resilience and ego-control. Professional caregivers rated children's sociability in pre-school using the Pre-School Behavior Inventory.

As predicted the AAI and the Parental Bonding Instrument were related. Only the AAI, however, yielded classifications that corresponded with the quality of infant-parent attachment. Furthermore, AAI classifications for mothers were related to maternal sensitivity: Secure mothers are more sensitive to their daughters than insecure mothers, but for boys this was not true. In addition, AAI classifications for parents were related to their children's socio-emotional development in the pre-school years. Secure
\end{abstract}

Requests for reprints should be sent to Marinus $H$. van IJzendoorn, Center for Child and Family Studies, Leiden University, P.O. Box 9555, NL-2300 RB Leiden, The Netherlands.

Preparation of this paper was supported by a PIONEER grant from the Netherlands Organization for Scientific Research (NWO) to the first author. Parts of this paper were presented at the Seventh International Conference on Infant Studies, Montreal (Quebec), 19-22 April 1990. The authors would like to thank Kees van Lieshout and his co-workers for their assistance in computing ego-resilience and ego-control scores. We thank Corine de Ruiter, Mary Main, and Erik Hesse for their constructive comments on an earlier version of this paper.

(C) 1991 The International Society for the Study of Behavioral Development 
mothers have children with more ego-resilience and less ego-undercontrol. Dismissing fathers have children who are rated as more aggressive, less social, and less timid than secure or preoccupied fathers. The AAI appears to be a promising instrument for measuring parental state of mind with respect to attachment relationships in a variety of natural settings.

\section{INTRODUCTION}

Attachment theory suggests that parents' childhood experiences are transferred to the next generation by way of their current internal working model of attachment relationships (Main, Kaplan, \& Cassidy, 1985). Main et al. $(1985$, p. 67) defined the internal working model of attachment as a set of rules "for the organization of information relevant to attachment and for obtaining or limiting access to that information..." This working model or "state of mind" with respect to attachment relationships is hypothesised to determine the way in which parents respond to their children's signals and needs, and therefore, to lead to corresponding sets of expectations in their children (Crowell \& Feldman, 1989; Main \& Goldwyn, in press). Insecure parents are believed to interact with their children in ways which minimally challenge the parents' internal working model of attachment, and therefore the need to adapt attachment-relevant information to their current state of mind may result in an inability to accurately perceive, interpret, and react to the attachment signals of their children (Main et al., 1985). Secure parents may be more sensitive to signals of distress, fear, or anxiety from their infants, because having worked through their past attachment experiences-or having had secure attachment experiences - they are supposed to be free to focus attention on their infants' needs.

George, Kaplan, and Main (1985) developed the Adult Attachment Interview (AAI) to assess an adult's current state of mind with respect to attachment relationships. The AAI is a semi-structured interview that enquires about early attachment experiences, probes for general as well as specific childhood memories, and asks for the parents' current evaluation of those memories (Main \& Goldwyn, in press). The coding system of the AAI leads to classification of adults into three categories. Autonomous or secure parents $(F)$ tend to value attachment relationships, and to regard them as influential for personality development, and yet are able to describe them coherently, whether or not attachment related experiences have been negative (e.g. loss, rejection) or positive. They do not idealise their parents and do not feel angry about their past experiences. Dismissing (D) adults tend to devalue the importance and impact of attachment relationships for their own lives, and tend to idealise their parents without being able to illustrate their positive evaluations with concrete examples of 
secure interactions. Preoccupied (E) adults are not able to describe their attachment history coherently, still being very much involved and preoccupied with the past. Some anger may be present in discussing current views of their parents. Dismissing and preoccupied adults are both considered to have an insecure internal working model of attachment. Through their incoherent discussion of experiences of trauma usually involving loss of attachment figures, some secure, dismissing, or preoccupied adults show indications that they have not yet completed or resolved their mourning process on the loss of an attachment figure. These adults are additionally assigned a classification as "unresolved" (U), which is superimposed on the three main categories (for details, see Main and Goldwyn, in press).

Classification of subjects is not based primarily on reported events in childhood, but rather on the degree to which the adult has a coherent understanding of those childhood experiences and the concomitant emotions raised by them (Main \& Hesse, 1990). In this respect, the AAI differs from instruments measuring adult attachment biographies that do not assess the coherence of the subjects' presentation or emotions connected with the childhood experiences being reported, i.e. the Parental Bonding Instrument (Parker, Tupling, \& Brown, 1979) and the Mother-FatherPeer scales (Epstein, 1983).

The relation between adult and infant attachment classifications has been studied by Main and Goldwyn (in press), and Ainsworth and Eichberg (in press) who focused on representations of loss in the AAI. In these studies, investigators have found considerable correspondence between parents' state of mind with respect to attachment, and the quality of their infant's attachment. In $69 \%$ to $80 \%$ of cases, secure adults had secure infants; dismissing adults had insecure-avoidant infants; preoccupied adults had insecure-ambivalent infants; and adults with unresolved mourning had infants judged disorganised/disoriented (Ainsworth \& Eichberg, in press; Main et al., 1985; Main \& Goldwyn, in press).

Few studies have documented the hypothesised relation between adult attachment (as measured by the AAI) and parental sensitivity to children's signals and needs. Haft and Slade's (1989) study on 14 families was exploratory and showed a relation between sensitivity and adult attachment. Autonomous mothers appeared to be more attuned to their babies than preoccupied or dismissing mothers. Crowell and Feldman (1988) showed that maternal attachment was related to the quality of mother's assistance during a problem-solving session: autonomous mothers were found more helpful and supportive of their infants than dismissing or preoccupied mothers.

It is unclear whether the AAI can be used in countries in which English is not a native language. $\mathrm{K}$. Grossmann, Fremmer-Bombik, Rudolph, \& K.E. Grossmann (1988) carried out the first cross-cultural study on adult 
attachment, but they revised the AAI, and constructed a new coding system, resulting in a different typology of attachment classifications. Grossmann et al. (1988) reported high percentages of correspondence between the revised AAI and infant attachment classifications $(85 \%$ and $78 \%$ in the Bielefeld and Regensburg samples respectively, for secure versus insecure attachments). They also found that in the Bielefeld subsample the autonomous mothers were more sensitive toward their infants during the first year than insecurely attached mothers. The question remains, however, whether the unrevised AAI with the original coding system is also applicable in countries in which English is not a native language. Cross-cultural application of the same instrument may stimulate meta-analyses and the establishment of its imposed etic validity (Berry, 1979). In this study, therefore, the original interview and coding system will be used, and some aspects of the validity of the unrevised AAI in The Netherlands will be assessed.

Furthermore, it is unclear whether the AAI is correlated with self-report instruments that do not take the coherence and integration of respondents' descriptions of their childhood experiences into account. Ricks (1985) showed that the Mother-Father-Peer Scales (Epstein, 1983) were related to infant attachment classification, but Benoit, Zeanah, and Barton (1989) did not find a relation with adult attachment classification. Ainsworth and Eichberg (in press) showed that real experiences with loss of attachment figures did not predict infant attachment, but that the coherence in talking about those loss experiences did (cf. Main \& Hesse, 1990). In this study, it is hypothesised that the AAI classifications share some variance with the Parental Bonding Instrument (PBI, Parker et al., 1979) which is based on subjects' self-reported childhood experiences. If some respondents indeed have had very positive attachment experiences in their childhood, the outcome of AAI and PBI will converge; but if some other respondents try to avoid the confrontation with their negative attachment experiences, they may idealise their past and emphasise the positive aspects of their attachments biography. Idealisation may not be discovered through the PBI, but in the AAI this idealisation will be evident in the incoherent way in which these subjects discuss their general impressions and the concrete illustrations of their childhood experiences. In this case, the outcome of both instruments will diverge. We, therefore, hypothesise that a self-report measure like the PBI only partly overlaps with the AAI, and is less powerful in predicting parental sensitivity or infant attachment compared to the AAI.

Although the relation between adult and infant attachment has been described in several studies, information about the relation between AAI and other aspects of children's socio-emotional development is still scarce (but see Crowell \& Feldman, 1988). In this study, we hypothesised that 
adult attachment will also predict the way in which children relate to their peers as reported by their professional caregivers, and deal with their emotions in complicated tasks or stressful situations according to their parents. It has been shown that the quality of infant attachment predicts later sociability (Sroufe, 1983), and the degree of ego-resilience and egocontrol (Waters, Wippman, \& Sroufe, 1979); Oppenheim, Sagi, \& Lamb, 1989; Van IJzendoorn, Van der Veer, \& Van Vliet-Visser, 1987), and it is suggested here that adult attachment is also related to these important dimensions of socio-emotional development.

In sum, some aspects of the validity of the AAI will be investigated in The Netherlands. First, convergence of the AAI with a self-report measure of childhood experiences, the PBI, will be tested. Secondly, the relation between adult attachment classification, caregivers' sensitivity and infant attachment classification will be described, and compared with the PBI. Lastly, the association between adult attachment classification and some aspects of pre-schoolers' socio-emotional development will be established.

\section{METHOD}

\section{Subjects}

Eighty children (53\% females) along with their mothers and fathers served as subjects in this study. The children were all healthy and born at full term. Infants' ages at the first session of measurements was 12 months (s.d. $=0.3$ ). At this first session, all families were intact, dual-earner families, with each partner working more than 10 hours per week. Five families that were excluded from an earlier report because mothers worked less than 15 hours per week (Goossens \& Van IJzendoorn, 1990), were included in this follow-up study. Average age of the mothers was 32 years (s.d. = 3), and fathers were on average 33.6 years old $($ s.d. $=3.5$ ). Socio-economic status of the families was assessed by summing up scores on 6-point rating scales ( $1=$ low) for professional status (Meijnen, 1977) of both parents, divided by four. Mean socio-economic status of the families was 4.9 (s.d. $=1.0$ ). Families were mainly middle class. At the second session, about two years later, 68 children (mean age: 41.5 months, s.d. $=1.4$ ) with their parents participated. Only a small number of mothers had stopped working outside the home during those two years $(n=10)$. Families who were not willing or able to participate in the follow-up study, did not differ from the participants in several respects: $t$-tests for SES $(t(73)=0.45)$, maternal sensitivity $(t(73)=0.14)$, and paternal sensitivity $(t(73)=0.42)$ did not reveal differences (for details about the operationalisation of "sensitivity", see the next section). 
Distributions for sex of child and infant attachment classification did not differ significantly either: For attachment to father $X^{2}(n=78$, d.f. $=1)=$ 0.80 ; for attachment to mother $X^{2}(n=76$, d.f. $=1)=0.25$; and for sex of infants $X^{2}(n=80$, d.f. $=1)=0.71$. The interviews were carried out in a subsample of 31 families ( 56 parents), that represented different attachment networks. This selection took place in order to study the differential consequences of different configurations of attachment relationships between a child and several caregivers. We will not report upon the issue of attachment networks in this paper (cf. Goossens \& Van IJzendoorn, 1990).

\section{PROCEDURE}

In the first assessment, infants were observed in the Strange Situation procedure and in a free-play session, with their mother, father, and professional caregiver separately (the sessions with the three caregivers were separated at least three months, and carried out in a counterbalanced order, see Goossens and Van IJzendoorn, 1990, for details). All observations were videotaped. At the second session, approximately two years later, children were again invited to our laboratory twice: Once with their mother, and once with their father, in counterbalanced order. During the second series of visits, the Parental Bonding Instrument (Parker et al., 1979) and the Nijmegen-California Child Q-sort (Block \& Block, 1980; Van Lieshout et al., 1983) were completed. Pre-school teachers were asked to complete the Pre-School Behavior Inventory (Hess et al., 1966). During the year following these visits to our laboratory, a portion of the families were asked to participate in the Adult Attachment Interview: 56 parents (27 mothers) were interviewed at home, almost always both parents at the same time in different rooms to prevent parents from influencing each other.

\section{Second-year Assessments}

Free-play Situation. The sensitivity of parents was assessed during 15 minutes of free-play with the infant. The parents were told to act as they pleased and to make use of the available toys. The videotaped recordings were coded by two independent coders using the 9-point rating scale developed by Ainsworth, Bell, and Stayton (1974). Three scores were given, one for each period of 5 minutes. Final scores consisted of a summation of ratings over the episodes divided by three. Intercoder reliabilities ranged from 0.81 (fathers) to 0.86 (mothers).

The Strange Situation. This structured laboratory procedure in which the parent and infant experience two separations and reunions in an 
unfamiliar setting, was employed in the way described by Ainsworth, Blehar, Waters, and Wall (1978). Infant responses to reunion with the parent were scored on 7-point interactive rating scales for proximityseeking, contact-maintaining, proximity-avoiding, and contact-resisting. On the basis of these scores, infant-parent relationships were classified as secure (B, 4 subcategories), insecure-avoidant (A, 2 subcategories), and insecure-ambivalent (C, 2 subcategories, or $A / C)$. Two coders scored $25 \%$ of the tapes independently. Percentage of agreement at the level of main and subgroup classifications for mother-infant and father-infant attachment ranged from $87 \%$ to $100 \%$. For the total group $(n=80)$, the distribution of infant-mother attachment classifications was: (A) 16; (B) 52; (C) 8; missing, 4. The distribution of infant-father attachment classifications was: (A) 23; (B) 51 ; (C) 4; missing, 2. In the subgroup of parents participating in the Adult Attachment Interview, the distribution of infant-mother attachment classifications was: (A) 10 ; (B) 15 ; (C) 1 ; missing, 1. For infant-father attachment classifications, the distribution was: (A) 10; (B) 19. Because of our selection rules for the AAI (see next paragraph), insecure-ambivalent relationships unfortunately were almost absent in this subsample (but not in the original sample).

\section{Fourth-year Assessment}

The Adult Attachment Interview. To assess parental state of mind with respect to attachment, the unrevised Adult Attachment Interview (AAI) including the questions about the adjectives to describe the relationship with the parents in childhood, was used (Main \& Goldwyn, in press). The AAI is a semi-structured interview designed to probe alternately for descriptions of relationships, specific supportive or contradictory memories, and descriptions of current relationships with the parents. The interviews were audiotaped and transcribed verbatim, and were classified for security of attachment history as presently discussed by the parent. Coding of the AAI according to the Main and Goldwyn coding system yielded three main attachment categories: secure/autonomous (F); dismissing (D); and preoccupied (E). If a parent appeared to be unresolved with respect to trauma, he/she additionally was assigned a $U$ classification. In this paper, we will focus on the DFE classifications, because of the relatively small sample size and because infant Strange Situation classifications (D) corresponding AAI classifications (U) were not available. The interviews were carried out in a subsample of 31 families (56 parents). For the purpose of a study on attachment networks-not reported here (but see Tavecchio \& Van IJzendoorn, 1987, for a theoretical foundation) -approximately equal numbers of infants from one of four groups were selected: Infants with secure attachment relationships to father, mother, and professional care- 
giver $(n=6)$; infants with B4-type (or "dependent") attachment relationships to those three caregivers $(n=7)$; infants with only insecure attachment relationships to their caregivers $(n=6)$; and infants with mixed insecure-secure attachment networks $(n=8)$. Another four infants were added to strengthen the power of the statistical tests. Those four infants were classified B-type attached with their caregivers. For the purpose of this study, the B4-infants were assigned to the secure group. Of the 31 families participating, two fathers were not willing to be interviewed, and in four other families the mothers did not participate. Thus, 29 fathers and 27 mothers $(n=56)$ were interviewed. Interrater agreement for 10 interviews was $90 \%$ for the four main categories. Coding was done without any knowledge of child characteristics and without knowledge of the distributions of infant-parent attachment classifications. The first author coded all interviews and had received training in scoring of the AAI by Mary Main, Erik Hesse, and Mary Ainsworth. At the time of the training he reached $82 \%$ agreement with Mary Main on 22 cases.

The Parental Bonding Instrument. Parker et al. (1979) designed the PBI to measure adults' experiences with their parents in childhood. They derived two factors from a set of 25 Likert-type items on childhood experiences: care and overprotection, indicating the degree to which respondents had experienced warmth in their relationship with their parents, and had had feelings of being overprotected. Parents were asked to rate their experiences with their father and mother separately on 4-point rating scales. In this study, we found a four-factor solution that was stable in both the mother- and the father-sample, and for experiences with both grandfather and grandmother. Four factors were derived on the basis of eigenvalues $(>1.00)$ and the Scree-test. Percentages of explained variance ranged from $54.2 \%$ to $59.8 \%$. Factors were: love, autonomy, unresponsiveness, and overprotection. Because two of the four unresponsiveness scales had alpha reliabilities lower than 0.60 , it was decided to exclude these scales from further analyses. Mean alpha reliability of the remaining scales was 0.82 (range from 0.70 to 0.89 ).

The Pre-School Behavior Inventory. The PSBI was used to assess children's social competence in the peer group. This instrument was originally designed by Hess et al. (1966) to assess behavioural differences between pre-school children within the normal, "non-clinical" range. The scale contained 20 items which had to be scored by pre-school teachers on 4-point rating scales. In this study we used only 18 items, and excluded one factor for achievement motivation. Four factors or scales remained: Aggression $(M=5.0$, s.d. $=1.9)$; Sociability $(M=12.9$; s.d. $=2.7)$; Timidity $(M=6.0$; s.d. $=2.3)$; and Independence $(M=9.9 ;$ s.d. $=1.8)$. 
In order to increase alpha reliabilities, 4 items had to be excluded. Mean alpha reliability for the four scales was 0.71 . Part of our sample of preschool teachers $(n=7)$ completed the PSBI for a second time, about two months later. Mean test-retest reliability was 0.76 (for details about the reliability and validity of the PSBI, see Van IJzendoorn, Kranenburg, Zwart-Woudstra, \& Van Busschbach, 1990).

The Nijmegen-California Child Q-Sort. Block and Block (1980) designed the California Child Q-Sort to measure ego-resilience and egocontrol. Resilience was defined as the competence to react flexibly but also persistently in problem situations. Control was interpreted as the disposition or threshold to repress or express impulses and emotions. Van Lieshout et al. (1983) constructed a Dutch version of the Q-Sort, the Nijmegen-California Child Q-sort of NCCQ, and validated the instrument for Dutch children from pre-school to 12 years of age. They reported excellent reliability and validity figures for the Dutch version of the CCQ. Fathers and mothers had to sort 100 behavioural descriptions, written down on cards, into nine categories, from "strikingly absent" to "strikingly present". Except for the middle category, all categories contained 11 cards after sorting. The resulting distribution was correlated with profiles of children with high resilience and weak control. The correlation coefficients served as the scores on resilience and (under)control, ranging from -1.0 to +1.0 (see Van Lieshout et al., 1983). The sorting was done by both parents individually, and scores were computed by Van Lieshout and his colleagues at the University of Nijmegen.

\section{RESULTS}

First, the convergent validity of AAI and PBI will be tested. Secondly, associations between $\mathrm{AAI}$ and $\mathrm{PBI}$ on the one hand, and parental sensitivity and infant attachment on the other, will be described to test whether the AAI is more powerful in predicting sensitivity and infant attachment than the PBI. As a preliminary step, the relation between parental sensitivity and infant attachment classification will be tested. Thirdly, we will test whether AAI classifications are meaningfully related to aspects of toddler's socio-emotional development as measured through the NCCQ and the PSBI. Discriminant function analysis (with the program DISCRIMINANT of SPSSX) is used to describe relations between categorical classifications and continuous measures. Interpretation of discriminant functions is based on a combination of an examination of the loading matrix of correlations between predictor variables and discriminant functions, and an evaluation of the group centroids related to the dependent variable yielded by the analysis (Tabachnick \& Fidell, 1983). In testing directional hypotheses, 
one-tailed tests of significance are computed. In some analyses, the dismissing and preoccupied AAI categories will be collapsed, to enlarge the power of statistical tests.

\section{Adult Attachment Interview and Parental Bonding Instrument}

In the group of 27 mothers, 8 subjects had to be classified as dismissing, 15 subjects as secure, and 4 subjects as preoccupied. In the group of 29 fathers, 8 subjects were classified as dismissing, 14 subjects as secure, and 7 subjects as preoccupied.

Discriminant function analyses were performed using PBI scales as predictors of membership in three AAI groups: dismissing; autonomous; and preoccupied attachment. PBI scales for parents' bonding to their mothers and to their fathers were used in separate discriminant analyses. Predictors were PBI scales for love, overprotection, and autonomy. Differences in socio-economic status were controlled for by first entering SES in the discriminant function analyses.

Two discriminant functions were calculated for PBI scales of mothers about their mothers, with a combined $X^{2}(8)=22.4 ; P<0.01$. After removal of the first function, a significant association between predictors and groups did not exist. Only variables contributing significantly to the functions are presented. The first function separated preoccupied subjects from the other two attachment classification groups (see Table 1).

Preoccupied mothers appeared to have experienced less warmth and autonomy from their mothers, and to have felt more overprotected compared to dismissing or secure mothers. Of the subjects, $74 \%(n=20)$ were correctly classified on the basis of the discriminant functions.

Two discriminant functions were computed for PBI scales of mothers about their fathers, with a combined $X^{2}(6)=18.8 ; P<0.01$. After removal of the first function, the second function did not significantly contribute to the separation of the groups. The first function maximally separated the preoccupied group from the dismissing and autonomous groups. Preoccupied mothers reported to have experienced more overprotection and less love from their fathers. Again $74 \%$ of the mothers were correctly classified on the basis of the functions; all preoccupied mothers were correctly classified.

Discriminant function analysis using PBI scales of fathers about their mothers did not yield significant functions. PBI scales of fathers about their father, however, appeared to discriminate between adult attachment groups. Two discriminant functions were calculated, with a combined $X^{2}$ $(4)=9.7, P<0.05$. After removal of the first function, the second function did not significantly discriminate between the groups. SES loaded on this 
TABLE 1

Discriminant Function Analyses of PBI Scales for Maternal Attachment Classification Groups $(n=27)$

\begin{tabular}{|c|c|c|c|c|c|c|c|c|c|}
\hline \multirow{2}{*}{ Predictors $^{\mathrm{a}}$} & \multicolumn{2}{|c|}{$\begin{array}{l}\text { Dismissing } \\
\quad(n=8)\end{array}$} & \multicolumn{2}{|c|}{$\begin{array}{c}\text { Autonomous } \\
\quad(n=15)\end{array}$} & \multicolumn{2}{|c|}{$\begin{array}{l}\text { Preoccupied } \\
\quad(n=4)\end{array}$} & \multirow{2}{*}{$\begin{array}{c}\text { Wilks' } \\
\text { Lambda }\end{array}$} & \multicolumn{2}{|c|}{ Corr. ${ }^{\mathrm{b}}$ with } \\
\hline & $M$ & $(s . d)$. & $M$ & (s.d.) & $M$ & $(s, d)$. & & $F I$ & $F 2$ \\
\hline \multicolumn{10}{|l|}{ Grandmother } \\
\hline SES & 4.4 & $(1.0)$ & 5.2 & $(0.8)$ & 5.2 & $(1.6)$ & 0.85 & 0.13 & 0.80 \\
\hline Love & 6.0 & $(1.8)$ & 6.0 & (1.5) & 9.9 & $(4.6)$ & 0.69 & 0.61 & -0.11 \\
\hline Autonomy & 13.6 & $(4.2)$ & 12.5 & $(3.5)$ & 14.4 & (1.9) & 0.96 & 0.13 & -0.32 \\
\hline Overprotection & 19.1 & $(2.0)$ & 20.0 & $(2.1)$ & 17.2 & (3.8) & 0.84 & -0.35 & 0.43 \\
\hline \multicolumn{10}{|l|}{ Grandfather } \\
\hline SES & 4.4 & $(1.0)$ & 5.2 & $(0.8)$ & 5.2 & $(1.6)$ & 0.85 & 0.08 & 0.79 \\
\hline Overprotection & 19.6 & $(2.2)$ & 21.4 & (1.9) & 18.4 & $(1.3)$ & 0.72 & -0.54 & 0.76 \\
\hline Love & 14.0 & $(4.6)$ & 15.2 & $(4.1)$ & 19.9 & $(8.4)$ & 0.86 & 0.43 & 0.26 \\
\hline
\end{tabular}

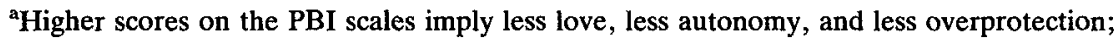
only scales contributing to the significant discriminant functions are presented.

${ }^{b}$ Correlations between predictors and first (F1) and second (F2) discriminant functions.

second function. Only the PBI scale "overprotection" was included in the first function, which maximally separated the dismissing group from the autonomous group. Dismissing fathers had experienced less overprotection from their fathers $(M=18.0$, s.d. $=1.5)$ than fathers in the autonomous group $(M=14.8$, s.d. $=2.9)$. Preoccupied fathers $(M=16.9$, s.d. $=2.6$ ) were in between these two groups.

In sum, overprotection and love appeared to be the most important PBI scales in discriminating between adult attachment groups. Preoccupied mothers appeared to be less positive about their childhood experiences than dismissing or autonomous mothers. Because the scale for overprotection (fathers) was based on less items than the scale for mothers (5 vs. 6), mean values have to be compared cautiously. Dismissing fathers scored a mean value of 18.0 on the overprotection scale ranging from 1 to 20 ; that is, dismissing fathers almost denied being overprotected.

\section{Adult Attachment, Infant Attachment, and Parental Sensitivity}

As a preliminary step, a two-way analysis of covariance on parental sensitivity with infant attachment classification (secure vs. insecure) and sex of infant as factors, and SES as covariate was calculated to test the association between parental sensitivity and infant attachment. The 
TABLE 2

Parental Sensitivity and Infant-Parent Attachment

\begin{tabular}{|c|c|c|c|c|c|c|c|c|}
\hline \multirow{4}{*}{$\begin{array}{l}\text { Infant-Parent } \\
\text { Attachment }\end{array}$} & \multicolumn{8}{|c|}{ Parental Sensitivity } \\
\hline & \multicolumn{4}{|c|}{ Mothers } & \multicolumn{4}{|c|}{ Fathers } \\
\hline & \multicolumn{2}{|c|}{$\begin{array}{c}\text { Girls } \\
(n=38)\end{array}$} & \multicolumn{2}{|c|}{$\begin{array}{c}\text { Boys } \\
(n=38)\end{array}$} & \multicolumn{2}{|c|}{$\begin{array}{c}\text { Girls } \\
(n=40)\end{array}$} & \multicolumn{2}{|c|}{$\begin{array}{c}\text { Boys } \\
(n=38)\end{array}$} \\
\hline & $M$ & $(s . d)$. & $M$ & $(s . d)$. & $M$ & (s.d.) & $M$ & $(s . d)$. \\
\hline Insecure $^{a}$ & 5.5 & $(1.2)$ & 6.5 & $(1.0)$ & 4.8 & $(1.1)$ & 5.5 & (1.1) \\
\hline Secure & 6.2 & $(0.9)$ & 5.5 & $(1.2)$ & 5.9 & $(1.3)$ & 5.8 & (1.0) \\
\hline
\end{tabular}

${ }^{a}$ The insecure-avoidant and insecure-ambivalent categories are collapsed into the insecure group.

ANCOVA showed a significant two-way interaction for mothers: $F(1,75)$ $=12.45, P<0.001$. Mothers of secure girls were more sensitive than mothers of insecure girls, but contrary to expectation this relation was reversed for boys (see Table 2).

The same two-way ANCOVA for fathers showed one significant (main) effect for infant attachment: $F(1,77)=6.62, P<0.01$. Fathers of secure infants were more sensitive to their infants' signals than fathers of insecure infants (see Table 3).

Two-way ANCOVAs were also calculated for the association between adult attachment classification and parental sensitivity. Adult attachment (secure vs. insecure) and sex of child were factors, and SES was a covariate. For mothers, this ANCOVA showed a significant two-way interaction: $F(1,26)=4.68, P<0.05$. Autonomous mothers of girls were more sensitive than dismissing or preoccupied mothers of girls, but maternal sensitivity did not differ for boys. For fathers, no significant main nor interaction effects were found (see Table 3).

The hypothesis regarding the correspondence between adult and infant attachment was tested with the chi-square statistic, and the strength of the association was tested with the Pearson correlation for $2 \times 2$ tables, phi. Cohen's kappas were also computed. In Table 4, the distributions of adult and infant attachment classifications (secure vs. insecure) are crosstabulated.

For mothers, 20 of $26(77 \%)$ infants were classified in the corresponding secure or insecure attachment category $X^{2}(n=26$, d.f. $=1)=5.23 ; P<$ 0.05 . The strength of the association was considerable: phi $=0.53(P<$ $0.01)$. For fathers, 18 out of $29(62 \%)$ infants were classified in the corresponding attachment category $X^{2}(n=29$, d.f. $=1)=1.08 ; P<0.30$; 
TABLE 3

Adult Attachment and Sensitivity

\begin{tabular}{|c|c|c|c|c|c|c|c|c|}
\hline \multirow{4}{*}{$\begin{array}{l}\text { Adult } \\
\text { Attachment }\end{array}$} & \multicolumn{8}{|c|}{ Parental Sensitivity } \\
\hline & \multicolumn{4}{|c|}{ Mothers } & \multicolumn{4}{|c|}{ Fathers } \\
\hline & \multicolumn{2}{|c|}{$\begin{array}{c}\text { Girls } \\
(n=15)\end{array}$} & \multicolumn{2}{|c|}{$\begin{array}{c}\text { Boys } \\
(n=12)\end{array}$} & \multicolumn{2}{|c|}{$\begin{array}{c}\text { Girls } \\
(n=18)\end{array}$} & \multicolumn{2}{|c|}{$\begin{array}{c}\text { Boys } \\
(n=11)\end{array}$} \\
\hline & $M$ & (s.d.) & $M$ & $(s . d)$. & $M$ & $(s . d)$. & $M$ & (s.d.) \\
\hline Insecure ${ }^{a}$ & 5.1 & (1.1) & 6.4 & $(0.6)$ & 4.9 & $(1.7)$ & 5.7 & $(0.4)$ \\
\hline Secure & 6.2 & $(0.6)$ & 6.3 & $(0.8)$ & 5.6 & $(1.2)$ & 6.5 & $(0.3)$ \\
\hline
\end{tabular}

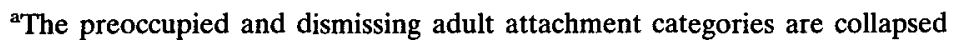
into the insecure group.

phi $=0.26 ; P<0.10$ ). Correspondences between adult and infant attachment on the level of the three main categories (DFE and ABC, respectively) were not significant.

To test the relation between PBI scales and infant attachment, analyses of covariance were performed on the PBI scales, with infant attachment (secure vs. insecure) and sex of infant as factors, and SES as covariate. These analyses did not yield significant results. To test the relation between PBI scales and parental sensitivity, hierarchical multiple regression analyses were performed with SES and the PBI scales as predictors. These analyses also did not yield significant results.

In sum, the AAI classifications for mothers corresponded significantly with infant attachment classification on basis of the Strange Situation. The

TABLE 4

Adult Attachment and Infant Attachment

\begin{tabular}{lcccccc}
\hline & \multicolumn{4}{c}{ Adult Attachment } \\
\cline { 2 - 6 } Infant & \multicolumn{2}{c}{ Mothers $^{\mathrm{a}}$} & & \multicolumn{2}{c}{ Fathers } & \\
\cline { 2 - 6 } \cline { 5 - 7 } & Attachment & Total & \\
\cline { 2 - 6 } & Insecure & Secure & & Insecure & Secure & \\
\hline Insecure & 8 & 3 & & 7 & 3 & 21 \\
Secure & 3 & 12 & & 8 & 11 & 34 \\
\hline Total & 11 & 15 & & 15 & 14 & 55 \\
\hline
\end{tabular}

${ }^{a}$ One infant-mother attachment classification was missing. 
AAI classification for mothers was related to maternal sensitivity, but only in the subgroup of girls; for boys, the relation was reversed. The AAI classification for fathers was not significantly related to infant attachment classification, nor to paternal sensitivity. The PBI scales for love, autonomy, and overprotection were not related to infant attachment nor to parental sensitivity.

\section{Adult Attachment and Toddlers' Socio-emotional Development}

Discriminant function analyses were performed using the NCCQ scales for resilience and undercontrol as predictors of membership in two AAI groups: secure and insecure internal working model.

Discriminant analyses were carried out separately for fathers and mothers. Differences in socio-economic status were controlled for by entering SES first in the hierarchical discriminant function analyses. For mothers, a discriminant function was calculated with a $X^{2}(n=27$, d.f. $=$ 3 ) $=8.28, P<0.05$ (see Table 5). Insecure mothers appeared to have less resilient and more undercontrolled children. Of the children, $70 \%(n=19)$ were correctly classified. In the group of fathers, NCCQ scales for resilience and undercontrol did not significantly discriminate between the AAI attachment classification groups. Discriminant analysis on three AAI groups (dismissing, autonomous, and preoccupied) for mothers did not reach the conventional significance level $(P<0.10)$; for fathers, this discriminant analysis was not significant either.

The NCCQ-scales measured children's socio-emotional functioning in situations in which the parents were present. The Pre-School Behavior Inventory (PSBI) measured children's socio-emotional adjustment to the pre-school environment in absence of the parents. Discriminant function

TABLE 5

Discriminant Analysis on Maternal Attachment Classification with NCCQ Scales and SES as Predictors $(n=27)$

\begin{tabular}{|c|c|c|c|c|c|c|}
\hline \multirow{2}{*}{ Predictors } & \multicolumn{2}{|c|}{$\begin{array}{c}\text { Secure } \\
(n=15)\end{array}$} & \multicolumn{2}{|c|}{$\begin{array}{l}\text { Insecure } \\
(n=12)\end{array}$} & \multirow{2}{*}{$\begin{array}{c}\text { Wilks' } \\
\text { Lambda }\end{array}$} & \multirow{2}{*}{$\begin{array}{c}\text { Corr. }{ }^{\text {a }} \text { with } \\
\quad F 1\end{array}$} \\
\hline & $M$ & $(s . d)$. & $M$ & $(s . d)$. & & \\
\hline SES & 5.2 & $(0.8)$ & 4.6 & $(1.2)$ & 0.92 & 0.47 \\
\hline Resilience & 571 & (155) & 483 & (195) & 0.94 & 0.40 \\
\hline Undercontrol & 140 & (151) & 232 & (170) & 0.92 & -0.46 \\
\hline
\end{tabular}

${ }^{a}$ Correlations between predictors and the discriminant function. 
TABLE 6

Discriminant Analysis on Paternal Attachment Classification with PSBI Scales and SES as Predictors $(n=29)$

\begin{tabular}{|c|c|c|c|c|c|c|c|c|c|}
\hline \multirow{2}{*}{ Predictors $^{\mathbf{a}}$} & \multicolumn{2}{|c|}{$\begin{array}{l}\text { Dismissing } \\
\quad(n=8)\end{array}$} & \multicolumn{2}{|c|}{$\begin{array}{c}\text { Autonomous } \\
(n=14)\end{array}$} & \multicolumn{2}{|c|}{$\begin{array}{l}\text { Preocc. } \\
(n=7)\end{array}$} & \multirow{2}{*}{$\begin{array}{c}\text { Wilks' } \\
\text { Lambda }\end{array}$} & \multicolumn{2}{|c|}{ Corr. ${ }^{b}$ with } \\
\hline & $M$ & $(s . d)$. & $M$ & $(s . d)$. & $M$ & $(s . d)$. & & $F 1$ & $F 2$ \\
\hline SES & 5.2 & $(1.3)$ & 5.2 & $(0.6)$ & 4.5 & $(1.1)$ & 0.91 & 0.29 & 0.34 \\
\hline Sociability & 11.5 & $(2.8)$ & 13.7 & $(2.0)$ & 13.2 & $(1.5)$ & 0.82 & -0.38 & 0.56 \\
\hline Timidity & 5.5 & $(0.8)$ & 5.8 & $(1.4)$ & 5.9 & $(1.7)$ & 0.99 & -0.12 & 0.07 \\
\hline Aggression & 5.9 & $(2.0)$ & 4.8 & $(1.5)$ & 4.3 & $(0.7)$ & 0.85 & 0.47 & -0.18 \\
\hline Independence & 10.3 & $(0.8)$ & 10.4 & (1.5) & 9.2 & $(1.5)$ & 0.87 & 0.35 & 0.42 \\
\hline
\end{tabular}

${ }^{a}$ Only predictors contributing to the significant functions have been presented.

${ }^{b}$ Correlations between predictors and first (F1) and second (F2) discriminant functions.

analyses were calculated for the PSBI-scales (sociability, timidity, aggression, independence) as predictors of the three AAI attachment classification groups. For mothers, the analysis did not show a significant discriminant function. For the AAI attachment classification groups of the fathers, however, two discriminant functions were calculated with a combined $X^{2}$ $(n=29$, d.f. $=10)=20.1 ; P<0.05$. The second function was not significant (see Table 6).

The first function maximally separated the dismissing fathers from the autonomous and preoccupied fathers. Dismissing fathers appeared to have children who behaved less social-verbal, less timid, and more aggressive in pre-school. Children of preoccupied fathers appeared to be somewhat less independent than those of autonomous and dismissing fathers.

\section{DISCUSSION AND CONCLUSION}

We found some evidence for the convergent and predictive validity of the unrevised AAI. First, the adult attachment classifications were associated with parents' self-report of their childhood experiences on the PBI (Parker et al., 1979). Preoccupied mothers report experiencing less love and more overprotection than dismissing or autonomous mothers. According to the coding system (Main \& Goldwyn, unpublished), preoccupied adults usually experienced lack of love, and moderate to extreme involvement (i.e. overprotection) from their parents. Results for the fathers are less clear-cut: Dismissing fathers indicate absence of overprotection from their fathers, which may be interpreted as an idealising description of a rather distant relationship with their father (cf. Main \& Goldwyn, unpublished). 
Second, parents' AAI classifications corresponded significantly with infant attachment classifications. Of maternal attachment classifications, $77 \%$ corresponded with the infant classifications, a result consistent with those of Main and Goldwyn (in press) and Ainsworth and Eichberg (in press). The correspondence between paternal and infant attachment was weaker $(62 \%)$, and is not in itself statistically significant. Furthermore, AAI classifications for mothers were associated with maternal sensitivity: Autonomous mothers were more sensitive to their daughters' signals and needs, but the opposite was true for boys. This result offers support for Main et al.'s (1985) suggestion that maternal sensitivity is the behavioural link between maternal and infant attachment only in case of girls (cf. Crowell \& Feldman, 1989). The unexpected result for boys merits replication before the validity is established. The play session is, of course, only one measure of parental sensitivity, and the particular measurement of sensitivity may be responsible for this equivocal outcome.

Third, the PBI scales did not predict infant attachment or parental sensitivity, emphasising once again the importance of the state of mind with respect to attachment, compared to reports of actual childhood experiences. Without taking the coherence and integration of descriptions and emotions of past attachment relationships into account, parents' childhood experiences are not related to the way in which they interact with their own children, at least in this non-clinical sample (cf. Kaufman \& Zigler, 1987).

Fourth, adult attachment classifications were predictably associated with aspects of children's socio-emotional development. Insecure mothers appear to have less resilient and more undercontrolled children. Children of dismissing fathers appear to be less social, less timid, and more aggressive in pre-school. Parental Q-sorts appēared to predict children's actual behaviour in stressful situations (Van Lieshout et al., 1983); these results can, therefore, not easily be ascribed to parental perceptions contaminating both AAI and NCCQ, although it would have been better if the professional caregivers would have been administered the sorting task also, to provide an independent source of information. Our results confirm and extend Sroufe's findings of a relation between infant security and later socio-emotional adaptation (Sroufe, 1983; Waters, Wippman, \& Sroufe, 1979; see also Oppenheim et al., 1989; Van IJzendoorn et al., 1987).

Although the AAI has proved to be a very promising instrument, not only in the United States but also in The Netherlands, a few caveats should be kept in mind. As in Main and Goldwyn's (in press) study, we found a lower percentage of agreement between the AAI classifications for fathers, and infant-father attachments compared to the AAI classifications for mothers, and infant-mother attachments. In our study, the correspondence between paternal and infant attachment was not significant. This 
result may be interpreted in the light of Bowlby's (1969) suggestion of a hierarchy in the organisation of internal working models of attachment figures (cf. Main et al., 1985). The model for the attachment relationship with the father may be lower in the hierarchy. This interpretation, however, is not supported by our data on the relation between paternal attachment and pre-school behaviour. The AAI classifications of fathers predicted the sociability, timidity, and aggressiveness of pre-schoolers, as observed by their teachers. Perhaps the hierarchy of models changes according to the domain in which children's adaptation is being assessed (cf. Bretherton, 1985; Oppenheim et al., 1989). An alternative interpretation would be that the AAI is less valid in case of fathers. These speculations surely need further research.

Furthermore, our design only allows for post hoc analyses instead of prediction of infant attachment classifications and parental sensitivity. Like Main and Goldwyn (in press) and Grossmann et al. (1988), we assessed adult attachment a few years after measuring infant attachment. Between the first and second phase of this study, parental internal working model of attachment could have changed, and, therefore, correspondence between infant and parental attachment could have decreased. If the experience of parenting a given child, however, does influence parents' memories and working models of their own experiences of being parented, the correspondence may also have increased. Predictive studies are needed to shed light on this issue. We also studied only a selected part of our original sample, and because insecure-ambivalent infant-parent attachments were almost absent, the generalisability of our results is restricted. In our case, we could not avoid selecting less insecure-ambivalent children than was to be expected on basis of the distribution in the original sample; estimations of correspondences may, therefore, be restricted to samples with insecure-avoidant and secure children. Lastly, we were not always able to show correspondences and relations at the level of the three-group distribution, and because of sample size we sometimes had to collapse the insecure attachment groups (Lamb, Thompson, Gardner, \& Charnov, 1985).

In sum, we found some evidence for the convergent and predictive validity of the AAI, especially in case of the mothers. Autonomous mothers report to have experienced more love and less overprotection in their childhood than preoccupied mothers. Furthermore, autonomous mothers more often have infants who are securely attached, and they are more sensitive to their infants' needs, at least in case of girls. In toddlerhood, children of autonomous mothers appear to be more resilient and to control their emotions better than children of insecure mothers. For fathers, the picture is more complicated, but we still found evidence that in certain domains, such as the pre-school setting, fathers' internal working 
model of attachment is predictably related to their children's functioning. We believe that further cross-cultural studies using the unrevised AAI in larger, unselected samples are warranted. In The Netherlands as well as in the United States, the parental internal working model of attachment as measured by the AAI, seems to be an important factor in determining the children's socio-emotional development.

Manuscript received 14 September 1990 Revised manuscript received 18 June 1991

\section{REFERENCES}

Ainsworth, M.D.S. \& Eichberg, C.G. (in press). Effects on infant-mother attachment of mother's unresolved loss of an attachment figure or other traumatic experience. In P. Marris, J. Stevenson-Hinde, \& C. Parkes (Eds), Attachment across the life cycle. New York: Routledge.

Ainsworth, M.D.S., Bell, S.M., \& Stayton, D.J. (1974). Infant mother attachment and social development: "Socialization" as a product of reciprocal responsiveness to signals. In M.P.M. Richards (Ed.), The integration of a child into a social world. Cambridge: Cambridge University Press.

Ainsworth, M.D.S., Blehar, M.C., Waters, E., \& Wall, S. (1978). Patterns of attachment, a psychological study of the Strange Situation. Hillsdale, NJ: Lawrence Erlbaum Associates Inc.

Benoit, D., Zeanah, C.H., \& Barton, M.L. (1989). Maternal attachment disturbances in failure to thrive. Infant Mental Health Journal, 10, 185-202.

Berry, J.W. (1979). Introduction to methodology. In C. Triandis \& W.W. Lambert (Eds), Handbook of cross-cultural psychology. Vol. 2, Methodology. Hertfordshire: Prentice Hall, pp. 1-28.

Block, J.H. \& Block, J. (1980). The role of ego-control and ego-resiliency in the organization of behavior. In W.A. Collins (Ed.), Development of cognition, affect and social relations. Minnesota Symposia on Child Psychology, Vol. 13. Hillsdale, NJ: Lawrence Erlbaum Associates Inc.

Bowlby, J. (1969). Attachment and loss. Vol. 1, Attachment. New York: Basic Books.

Bretherton, I. (1985). Attachment theory: Retrospect and prospect. In I. Bretherton \& E. Waters (Eds.), Growing points of attachment theory and research. Monographs of the Society for Research in Child Development, 50 (1-2, Serial No. 209), 3-37.

Crowell, J.A. \& Feldman, S.S. (1988). Mothers' internal models of relationships and children's behavioral and developmental status: A study of mother-child interactions. Child Development, 59, 1273-1285.

Crowell, J.A. \& Feldman, S.S. (1989). Assessment of mother's working models of relationships: Some clinical implications. Infant Mental Health Journal, 10, 173-184.

Epstein, S. (1983). The mother-father-peer scale. Unpublished manuscript, University of Massachusetts at Amherst.

George, C., Kaplan, N., \& Main, M. (1985). An attachment interview for adults. Unpublished manuscript, University of California, Berkeley.

Goossens, F.A. \& Van IJzendoorn, M.H. (1990). Quality of infants' attachment to professional caregivers: Relation to infant-parent attachment and daycare characteristics. Child Development, 61, 832-837.

Grossmann, K., Fremmer-Bombik, E., Rudolph, J., \& Grossmann, K.E. (1988). Maternal 
attachment representations as related to patterns of infant-mother-attachment and maternal care during the first year. In R.A. Hinde \& J. Stevenson-Hinde (Eds), Relations between relationships within families. Oxford: Clarendon Press, pp. 241-260.

Haft, W.L. \& Slade, A. (1989). Affect attunement and maternal attachment: A pilot study. Infant Mental Health Journal, 10, 157-172.

Hess, R.D. et al. (1966). Techniques for assessing cognitive and social abilities of children and parents in project Headstart-Report No. OE0519. Chicago, Ill: Chicago University Press.

Kaufman, J. \& Zigler, E. (1987). Do abused children become abusive parents? American Journal of Orthopsychiatry, 57, 186-192.

Lamb, M.E., Thompson, R.A., Gardner, W., \& Charnov, E.L. (1985). Infant-mother attachment: The origins and developmental significance of individual differences in Strange Situation behavior. Hillsdale, NJ: Lawrence Erlbaum Associates Inc.

Main, M. \& Goldwyn, R. Adult attachment coding system. Berkeley: University of California (unpublished MS).

Main, M. \& Goldwyn, R. (in press). Interview-based adult attachment classifications: Related to infant-mother and infant-father attachment. Developmental Psychology.

Main, M. \& Hesse, E. (1990). The parents of insecure-disorganized/disoriented infants: Observations and speculations. In M. Greenberg, D. Cichetti, \& M. Cummings (Eds), Attachment in the pre-school years. Chicago, Ill: University of Chicago Press, pp. 161-164.

Main, M., Kaplan, N., \& Cassidy, J. (1985). Security in infancy, childhood, and adulthood: A move to the level of representation. In I. Bretherton, \& E. Waters (Eds), Growing points of attachment theory and research. Monographs of the Society for Research in Child Development, 50 (1-1, Serial No. 209) 66-106.

Meijnen, A.W. (1977). Maatschappelijke achtergronden van intellectuele ontwikkeling [The influence of family characteristics on the development of intelligence in children from 6 to 8 years]. Groningen: Wolters-Noordhoff.

Oppenheim, D., Sagi, A., \& Lamb, M.E. (1988). Infant-attachments on the kibbutz and their relation to socio-emotional development four years later. Developmental Psychology, 24, 427-433.

Parker, G., Tupling, H., \& Brown, L.B. (1979). A parental bonding instrument. British Journal of Medical Psychology, 52, 1-11.

Ricks, M.H. (1985). The social transmission of parental behavior: Attachment across generations. In I. Bretherton \& E. Waters (Eds), Growing points of attachment theory and research. Monographs of the Society for Research in Child Development, 50 (1-2, Serial No. 209), 211-230.

Sroufe, L.A. (1983). Infant-caregiver attachment and patterns of adaptation in preschool: The roots of maladaptation and competence. In Perlmutter, M. (Ed.), Development and policy concerning children with special needs. Minnesota Symposium on Child Psychology, Vol. 16. Hillsdale, NJ: Lawrence Erlbaum Associates Inc.

Tabachnick, B.G. \& Fidell, L.S. (1983). Using multivariate statistics. New York: Harper \& Row.

Tavecchio, L.W.C. \& Van IJzendoorn, M.H. (1987). (Eds). Attachment in social networks. Amsterdam: Elsevier Science Publishers.

Van IJzendoorn, M.H., Van der Veer, R., \& Van Vliet-Visser, S. (1987). Attachment three years later. Relationships between quality of mother-infant attachment and emotional/ cognitive development in kindergarten. In L.W.C. Tavecchio \& M.H. IJzendoorn (Eds), Attachment in social networks. Amsterdam: Elsevier Science Publishers, pp. 185-225.

Van IJzendoorn, M.H., Kranenburg, M., Zwart-Woudstra, H., \& Van Busschbach, A. (1990). The Pre-School Behavior Inventory: Reliability and validity. Leiden (The Netherlands): Center for Child and Family Studies. 


\section{VAN IJZENDOORN ET AL.}

Van Lieshout, C.F.M. et al. (1983). Zelfstandigheidsontwikkeling in het basisonderwijs [Autonomy in elementary school]. Nijmegen (Intern Rapport 83 ON O4, SVO-project BS560).

Waters, E., Wippman, J., \& Sroufe, L.A. (1979). Attachment positive affect, and competence in the peer group: Two studies in construct validation. Child Development, 50, 821829. 